\title{
Building Memory
}

\author{
Jeff Malpas
}

\section{Introduction: architecture and ontology}

What is the ontology of architecture? One way to understand this question is to take it as asking after the basic elements of architectural practice - the basic elements of design or construction. Yet the question of the ontology of architecture can be viewed in another way also, as directed at an understanding of the being of architecture, at uncovering its proper limits and grounds (see Malpas 2012a). It is in this latter sense that I wish to put the question here. Moreover, when taken in this sense, it seems there can be only one answer: more so than any other mode of human activity, architecture has its being in the human engagement with place, and more specifically, in the engagement with place as opened up through building. I say "place" rather than space, because it is place, as I note below, that is the more basic concept here. Moreover, in talking about architecture as founded in an engagement with place, I do not mean that architecture is simply to be understood as "place-making" - architecture is as much a response to place, a conversation with place, as it is a making of place.

Although the claim might surprise some, it seems to me that the question concerning the ontology of architecture is not often raised. Much contemporary reflection on architecture, when it goes beyond technical and professional concerns, remains at the level of architectural narrations that are more concerned with the deployment and elaboration of metaphorical and metonymic constructions than with the analysis of the ontological underpinnings to architectural practice. The proliferation of architectural discourse around notions of "criticality" (see e.g. Hays 1984), or "post-criticality" (see e.g. Somol \& Whiting 2002, and Baird 2004), has little to do with ontology in either of the senses I have invoked here, being focussed instead on the political and discursive positioning of architecture. Such discourse may well be productive in a variety of ways, but it has little directly to do with any increased insight into matters ontological. The tendency that is exemplified here is not restricted to discussions of "criticality" and "post-criticality" alone. For the most part, and in spite of some notable exceptions, when contemporary architectural discourse extends beyond practical design concerns, it seems characterised by a preoccupation with contingent discursive and rhetorical formation, in particular a concern with architecture's own discursive self-formation and self-representation - especially as this is bound up with the character of modernity (what the German term Neuzeit understands as "the time of the new") - rather than with questions concerning architecture's enduring grounds or limits.

What happens when we turn back to the ontology of architecture, and especially when we try to understand architecture in terms of the engagement with place through building? What underpins this engagement and in what is it founded? It is my contention that any such inquiry must pay special attention to the connection of place, and hence also building, with memory. The connection of memory with place is not peripheral nor is it contingent. Place and memory are integrally connected such that one cannot understand one without reference to the other. Any inquiry into the ontology of architecture that attends to the character of architecture as an engagement with place must, therefore, give special attention to memory. Indeed, one might say that architecture cannot itself be understood unless its own connection to memory is acknowledged and articulated, and so the inquiry into the ontology of architecture must take the form of an inquiry into 
the relation between memory and place. The argument that I will advance here can thus be simply stated: there is no place without memory; no memory without place; and since there is no architecture that is not engaged with place, neither is there architecture that is not engaged with memory. What matters, however, are the considerations that support and articulate this set of claims (as well as the consequences that follow from them), and the most important considerations concern the connection between memory and place, so let me begin there.

\section{Memory and place - place and memory}

There is a long tradition that connects place to memory. It is a connection famously exemplified in the ars memorative - the art of memory - and the associated "method of loci" according to which memory is enabled through the connecting of particular images or ideas to be remembered with specific locations (see Yates 1974). It is also a connection that appears in the work of many twentieth-century thinkers. In the work of Gaston Bachelard (1969), for instance, memory is explored as it is given in the intimacy of domestic places; in the writings of Walter Benjamin, memory appears in its embeddedness in the materiality of things, and especially in the materiality of the city, in its buildings and streets (see Malpas 2007). The exploration of memory is also central to the work of Marcel Proust (1995) and, more recently, W. G. Sebald (1998) - the one surely standing in an essential relation to the other, both as it arises in the form of public history and private recollection, and as it is formed in and through specific locations and locales from Combray to Paris, from Norfolk to Vienna. Yet although the connection of memory to place is clear in these thinkers and writers (and in the work of many others, including those working within what is now known as "material culture studies" - see for instance Hicks \& Beaudry 2010), the exact nature of that connection, and whether it is a necessary or a contingent one, often remains much less clear. Moreover, in spite of the work of writers and thinkers like Proust, Sebald, Bachelard, Benjamin, and others, there is also a common tendency to assume that because memory is of the past, so memory is primarily a temporal phenomenon rather than having any connection to the topographic, that is, to place.

Even if memory were taken to have a special relation to time, still this would not itself imply the priority of that relation over the relation of memory to place. The reason is simple: time does not stand apart from place any more than does space. Indeed, both time and space, even while they may be opposed to one another, should both be understood as grounded in place, and perhaps even as abstractions from it (see Malpas 2012b). Nonetheless, the tendency to think of memory as primarily temporal is undoubtedly one of the factors that encourage a forgetfulness of the essentially topographical character of memory. This tendency is in turn underpinned by what I refer to as the "temporalist" prejudice within modern thought, according to which subjectivity is itself understood as essentially temporal in character (see Malpas 2010a \& 2013). Temporality, and so also memory, is thus viewed as tied to the subjective interiority of human existence whilst spatiality is associated with objective exteriority. There is a much longer story to tell here, but if we retain the focus on memory alone, and especially on the idea that memory might be tied primarily to time rather than place, then even if we leave aside the complication that consists in the dependence of time on place, the prioritisation of the temporal still gives rise to a problematic conception of memory. Edward Casey makes the point that the focus on temporality leaves out the need for embodiment, and embodiment requires emplacement (2000: 182), but, more fundamentally, I would argue that, as memory is meaningful or contentful, so memory is only constituted through the embeddedness of the one who remembers in place, while 
the necessary interdependence that obtains between self and place, coupled with the essential role of memory in the formation of the self, means that memory and place are thereby also brought into intimate relation (see Malpas 1999).

Put briefly, the argument at issue here is one that looks to the holistic constitution of meaning or content as this applies to memory no less than it does to beliefs, desires, actions and so forth. As meaningful or contentful memories are embedded within networks of memories and attitudes, so those networks are also embedded in, and inter-related with, the objects and entities in the world that cause them and that are also their objects. The very idea of meaning or content thus depends essentially on the connectedness of those who remember - and who also act, think, believe, and experience - to the world, and so to objects and entities in the world. On this basis one might say that the "mind" is itself externalised, and meaning and content have to be understood, not as given in some separate, "inner" realm, but only in the space of worldly engagement. Inasmuch as the self is constituted through the dynamic integration, even if always impartial and incomplete, of memories, beliefs, actions and the rest, so the self also turns out to be constituted through its worldly involvement - who and what we are is thus dependent on where we are. Memory cannot be prised away from the world any more than can the self, but more than this, memory is also given in the world, in the concrete materiality of things, since it is there that self and identity, meaning and content, are jointly constituted and articulated (see Malpas 2010b).

Memory is thus only to be found through the placed materiality of the world and this is equally true of both private and public memory. Understood more explicitly in relation to place, one can say that place is precisely that which gathers self, others, and things in a way that opens them both to the world and to each other. The placed materiality of memory that appears here has a number of consequences - although they are consequences that go against some established and taken-for-granted assumptions in many contemporary treatments of memory. First, memory is not "subjectively" determined nor does it belong to the "subject" alone. By this I mean that memory is not something that is to be understood as merely a product of subjective experience. Certainly memory is an essential element in our interior life, but it is not constituted only in terms of such interiority. Memory arises through our interactive engagement with the world in which we find ourselves - an involvement that does not come after the formation of the self, but is the very means by which the self is formed. In this respect we make ourselves through our engagement in the world, which implies also that we do not wholly make ourselves, since, as I indicated above, who and what we are is itself a function of the world in which we are engaged. Second, memory is not socially "constructed", in spite of the prevalence of such social constructivism in contemporary thought. Sometimes, of course, social constructivism entails no more than the idea that what is taken to be constructed in this way arises through a process that necessarily involves the "social" (almost all human activity depends upon language, and since language is intrinsically social, so one might say that almost all human activity is "constructed" socially because it is "constructed" linguistically - although here "construction" seems to be used as a synonym for "shaped through or in relation to". Such constructivism is relatively unproblematic. More often, however, social constructivism, and here we can include the supposedly socially constructed character of memory, involves the stronger idea that memory is determined by the social, that it is, in effect, a product of social forces alone. The difficulty, however, is that if the social constructs memory, it is equally true that memory constructs the social - that is, only in and through memory is sociality even possible. More broadly, and given the interconnection of memory with place, 
one ought to say, not that memory is determined by either the subjective or the social (or the "intersubjective"), but rather that subjectivity and sociality (and also objectivity - see Malpas 1999) emerge only within the overarching structure of place. Place is just that within which self and the social are reciprocally constituted, and in which they are both constituted in essential relation to the materiality of the world.

Memory, one might say, begins in place, yet so too does place begin in memory. To be in place is already to remember. Place itself never appears other than as it is already taken up in memory, even if the memories that attach to any particular place are fragmentary, associative, or recent. Moreover only on the basis of memory are we oriented, and only as we are oriented are we placed. We thus find ourselves in the world, which means we only find ourselves at all, in and through memory, and although memory is itself only to be approached in and through place, we cannot approach place independently of memory either. It is as remembered that place first appears, and even the experience of place is always suffused with memory, shaped by memory, directed by memory. There is thus no place without memory; no memory without place (see Malpas 2013).

In an important and often overlooked sense, memory is always nostalgic - and so always melancholic. This is so, not in the sense that memory involves a desire to regain what cannot be regained (what is sometimes termed "restorative nostalgia"), but rather in the sense that memory always involves a sense of loss (hence the melancholia) - to remember is to attend to what is past, what is no longer present as it was, but if present still, is present in a different way. To attend to what is remembered is thus to attend to the dynamically unfolding character of place. The nostalgia that is associated with memory - and as genuinely nostalgic so it combines a sense of 'home' (for the loss at issue here is also a loss directly related to the self) together with the pain that comes from the inevitable estrangement from home - is thus an essential feature of human engagement in the world. It cannot be escaped any more than we can escape the world or ourselves (see Malpas 2012a). The nostalgic is that which marks the dynamic opening of the world in place in terms of both freedom and limit - and so too in terms of our own character as active beings and yet also as possessed of an existence that is finite and fragile. From an ethical perspective, it is here that the idea of responsibility has its essential origin.

Bachelard asserts, and Casey repeats the claim, that memories do not move (Casey 2000: 214-215). Yet even if this is so, memory is always at the beginning of movement, containing the possibility of movement within it. Casey argues that the supposed immobility of memory is given through its connection to place. Thus places fix memory (Casey 2000: 215). Yet as it is only in and through places that memories have form, so places are themselves given form only in and through memory. The idea that places fix memory seems to presuppose an asymmetry in which it is place that has determinacy and fixity. Yet neither memory nor place has a fixity that belongs to either of these alone - memory always carries multiple possibilities that accord with the multiple possibilities of the places memory opens up and in which memory is itself opened. This point is an important one, since it is often assumed that memory and place possess, if not a fixity, then a perduring character or even a determinacy that is alien to both. Precisely because of the relationality that characterises memory and place, as well as the self, none of these have an absolute determinacy either over time or at a time. Place, and memory and the self with it, are dynamic structures - neither we nor our memories are fixed in place like insects in amber, and places are not static structures that stand as the unmoving backdrops to our lives. 
The latter is one reason to be wary of some appropriations of Heideggerian thought that emphasise the character of place as a source of authentic and enduring rootedness - if we do indeed look to Heidegger, we should attend to his own emphasis on the character of homecoming as always a return to the indeterminate and the questionable. This does not mean that there is nothing at issue in the idea that there is a human "need for roots", as Simone Weil put it (1971; see also Améry 1998), but only that this is a need that demands a more careful and complex examination than it is usually accorded. Moreover, although home is a place primarily characterised in terms of the possibility of rest and repose, of internality and intimacy, it is never wholly so - its "homely" character is never secure and may contain within it the very deepest melancholy. One might thus be led to claim that home is always "uncanny", but we have to be careful about what this is taken to mean. The "uncanny" has become such a common term with which to conjure the spirits of modernity - and perhaps nowhere more so than in relation to architecture - that the term is in danger of losing any real meaning. The "uncanny" is now used - as in Anthony Vidler's (1992) nevertheless intriguing discussion of "the modern unhomely" - to encompass a wide range of different, even if related, moods, attitudes, tropes, and dispositions. Moreover, not all of these are specific only to the modern - and here the tendency to view the modern as in some sense "exceptional" (as indeed "new") is indicative of the same disregard of ontological considerations as that to which I alluded above. Certainly the modern is different, but its difference has to be understood against the background of that which is constitutive of the possibility of historical existence as such. Inasmuch as "home" contains within itself the capacity for its own disruption as home, then this does not show that home is therefore "unhomely", but rather that home is indeed a mode of place, and as such, contains an essential indeterminacy and openness within it, even an essential fragility and tendency towards loss - home is never just home, just as no place remains utterly self-enclosed within its boundaries.

Memory is impossible without forgetting, just as the salience of place is impossible without its withdrawal. As the coming into salience of something within the space opened up in place is also for other things to withdraw into the background (a phenomenon familiar from phenomenological analysis as well as studies of sensory perception), so memory and forgetting are not separate, but two sides of the one process. To forget is to remember, and to remember is to forget. This is one reason why the idea of an "absolute" or "complete" memory in which there is no forgetting - the sort of "memory" that one finds exemplified and explored in Borges (1962), as well as Luria (1987) - is perhaps best understood, not as memory in any genuine sense at all, but rather as a distorted form of memory in which all that is left is a debilitating retentiveness that undermines the capacity for action and the sense of self.

No memory is completely private, because all memory is placed, and the placed character of memory means that every memory has some dimension that is accessible to others, even as it also has a dimension that resists such access. In part this reflects the fact that memories are related differently to different modes of human identity and narrative - to identity and narrative as personal and as collective. Memory is also given in ritual and event - it is performed - and the performance of memory connects modes of personal and collective life. We see this in forms of collective celebration - both those celebrations and festive occasions where we celebrate collectively as well as when we celebrate in the same or similar ways among family, with friends, or within other groups. Once again the performative character of memory relates directly to the dynamic and indeterminate character of place as well as memory, and so also, one might say, to the performativity 
of built form. If place is not static, but dynamic, then neither is the built. Indeed, it is largely through the dynamic and performative character of place, memory, and building that these are bound together. The ontology that appears here is thus an essentially relational and dynamic one, and it is this ontology that belongs to place, to memory, to building, and to architecture. It is moreover an ontology that remains irrespective of whether or not it is recognised or represented. What grounds and limits existence is often just that which is forgotten, or even denied, within existence.

\section{The memory of the built}

This view of the relation between memory and place that I have sketched here is one that I have sometimes characterised as a form of "romantic materialism". It is romantic in that it holds that materiality appears as material only through being taken up in and through the meaningful and the remembered, whilst it is materialist in that it holds that meaning and memory are, in turn, given in the very materiality of things. If we turn back to architecture, and particularly to a consideration of the built form of the architectural (since my concern here is with the materiality of memory as given in and through place), then such "romantic materialism" suggests that we should think of buildings not as inert structures that stand apart from remembrance, from felt experience, sentiment, or affect, but as constituted romantically and materially at one and the same time. In terms of memory, buildings carry memory as an essential and inevitable part of what they are, and they do this in several ways.

The very sensory properties of built forms - their shapes, structures, and materials - have a memorial character. This is not only true of the sensory properties of buildings as they may be given visually (although this is certainly important), but also in terms of other modes of sensory presentation. The smell of a building, the touch of its surfaces and shapes, the acoustic properties of its spaces - all of these contribute to memory, but also serve as the carriers and triggers for remembrance. Sometimes the relation to memory may be direct - this particular angle of a wall, this juxtaposition of doorway and window, this fall of light, may immediately evoke a memory of our own. Sometimes the relation to memory may be via certain archetypal forms or schemas that are typically felt and recognised through generalised modes of bodily engagement and responsiveness. The complex interplay of memory in building, as well as the role of the body here, is given explicit recognition in Peter Zumthor's work and writing, so much so that, for Zumthor, architecture might be seen to be constituted in terms of bodily remembrance (see Zumthor 1999). (Zumthor is particularly attentive to the remembrance of certain archetypal forms, hollows, mounds, caves, platforms, nests and tents, as exemplified in the womb-like interior space of his recent Bruder Klaus Chapel.) Memory is given, not only in the felt or sensed qualities of a building - in the concrete qualities of its presencing - but also in its symbolic and semiotic elements, whether they belong to the particularities of site, orientation, ornament or style. In one sense, such elements are not strictly the material of memory - at least not insofar as they remain at the level of the abstract or generic - but since they are invariably embedded in, and evocative of, collective as well as personal history and remembrance, and so also given specific materiality, so they never stand wholly apart from the memorial, and from the shared understanding of forms and structures that are part of materialised cultural memory and tradition. Often the forms of memory that are at work here are so mundane and commonplace that they are readily overlooked - the remembered narratives that are encoded in the floor plan of a building and the arrangement of rooms within it or that differentiate different 
aspects of a building's relation to the street play a basic role in the functioning of buildings and in our ability to engage with them. Memory is given too in the inscriptive and dynamic elements of building - in the effects of weathering, decay and renewal, of extension and re-use (see Leatherbarrow \& Mostafavi 1993). The ruin, or the evocation of ruination, provides an extreme instance of this mode of presentation of the built as the concretisation of its own history, and so of the history of a place, as well as of building as itself the operation of the historical.

Built form is always remembered form. The opening up of place through building that occurs in the architectural engagement with place is thus also an opening up of memory. Consequently memory is itself formed in and through building. The infusing of building with memory and memory with building means that building is never just "objective", and never just "subjective" either - it always operates between the two and in the space in which both are themselves opened up. At the level of Australian domestic architecture, Richard Leplastrier's "Lovett Bay House" at Pittwater, New South Wales, built on the site of an earlier dwelling destroyed by wild fire, provides a striking illustration of a mode of architectural practice that consciously draws on memory, building memory into the forms it constructs, allowing memory to emerge in and through the site - and doing so on a multiplicity of levels (see Fig. 1).

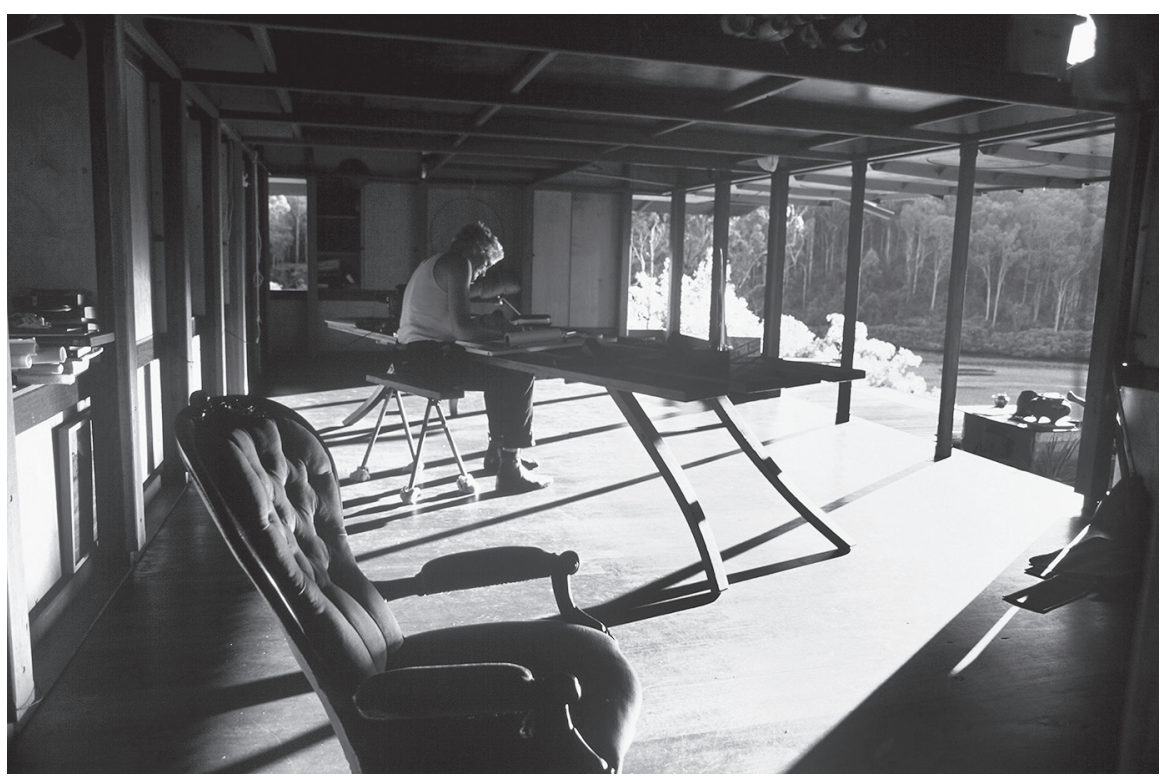

Here memory also means a memory of continuity of settlement - the memory of a belonging that is not and cannot be proprietorial. As Leplastrier writes:

... the house continues a history of simple living on the site, which I suspect has continued for thousands of years: small shells that litter the place give testament to that fact. The form of the building is simple - its central core room restrains a broad cantilever roof that surrounds the building, the lack of columns allowing the line of the landscape to continue unbroken. Being inside the house is like sitting under a strong over-hanging tree. (Quoted in Lehtimaki \& Neuvonen 2004: 18)

For all this, however, much of the contemporary practice of building, and of architecture, often remains enmeshed in a "presentism" that refuses memory as it
Fig. 1 Lovett Bay House, Richard Leplastrier. [Photo: Leigh Woolley, 1998 - thanks to Richard Leplastrier for allowing the image to be reproduced.] 
frequently ignores place. Such "presentism" can be discerned in a particular way in the material forms of many modern and contemporary buildings. If memory is given in and through sensory quality, which means through the materiality of things, a materiality that is always evident in surface, and depth of surface, then one of the features of many modern and contemporary buildings is their tendency towards the effacement or loss of such materiality and depth of surface. The use of glass is one of the ways this is sometimes manifest (although glass also has "surface effects" of its own), but it is evident too in the widespread use of a range of homogenous and homogenising materials, from colour-bonded steel and rendered finishes to pre-cast concrete panels. Often the use of such materials is driven by concerns of efficiency or cost, but sometimes their use is also the result of stylistic and aesthetic considerations that are indeed geared to certain conceptions of the modern and the new. Moreover, the loss of depth in surface materiality might also be seen to give a heightened emphasis to more formal properties of built structures, so that the building comes close to being itself almost an abstraction, an "idea", rather than a materialised "thing". Within modernist architecture, one can sometimes discern a tension between the tendency to prioritise such abstracted form in the built and a continued concern with material quality - even in the work of such a committed modernist as Mies van der Rohe who emphasises formal structure on the one hand and yet still makes use of marble and other materials with a high "depth of surface" on the other (although these comments only touch on a much larger set of issues that are relevant here - see especially Andrew Benjamin 2006).

Partly because of the tendency toward the loss of surface depth, and partly because of the associated tendency towards a certain form of abstraction, so contemporary buildings often seem designed to appear more as images of buildings than as the real buildings they nonetheless are - images of buildings that come from nowhere and belong to no-one. If such buildings evoke the uncanniness so often said to characterise the built forms of modernity, then this is largely because of the way in which they appear as their own doubles - refusing to allow that there is any building other than the one that is imagined or represented. As is the case with so much of modernity's own self-representation, the uncanniness that appears here is actually a form of forgetting - a forgetting that, in its more sophisticated forms, has become almost wilful, extolling its own forgetfulness as now a virtue.

The idea of the building as its own image, its own representation, or that its character as a building may be submerged in its imagistic or representational character, itself constitutes another form of architectural presentism - and here the architectural tendency to engage in 'story-telling' returns. There can be no doubt that story and memory are related - as are narrative and place - but there are stories and stories, and not every story secures or is secured by memory, just as not every story told about a place belongs to it. Many (although certainly not all) of the stories told about buildings and the designs that supposedly underpin them seem to depend on taking the built form as something other than it is - not as a concrete form that does indeed engage with a certain place, but rather as almost a piece of text, carrying a script that is to be read in one way and one way only. Understood thus, the building as "text" (or as "image") is no longer constituted by its materiality, but rather becomes that which determines its own materiality through being inscribed into it. It is thus that the materiality of so much built form recedes, in modernity, in the face of the primacy of the image, the text, the representation. There is indeed nothing outside the representational, and the representation has become the form of the architectural. 
The dominance of what I have here called 'story-telling', but which is actually the dominance of a certain form of narrativist textualism or representationalism, and the problematic character of that dominance, should not be confused with the centrality of narrative form in meaning production in general. There could be no design, no building, no engagement with place, were it not for the narrative. Yet, to repeat: there are narratives and narratives. The centrality, even indispensability, of narrative does not licence any and every narrative or any and every narrative practice. The question to be asked of every narrative is the extent to which it is indeed embedded in that which it also aims to narrate - to what extent does the story belong to the material and the material to the story. In many cases, the connection at issue is tenuous at best, and the materiality of the built is lost in the narrated fabric with which it is clothed.

The materiality that is obscured or forgotten in so many architectural narrations is not only the materiality of the built as it evades any and every narrative (even as it also comes to appearance in and through narrative), but also the materiality of the built as it contains and sustains memory. In this respect, however, the fabricated narrative that has no genuine foundation in the material and concrete is unlikely itself to be remembered. There is something especially ironic here, since often the design intention that is encoded in a particular architectural narrative is one that it is usually expected will continue to shape the life of the building even after construction. In some cases, this can signify another form of architectural presentism in terms of the idea that a present narrative (regardless of the strength of its embeddedness in the materiality of a building) might be able to determine the future narratives, and so the future uses and meanings, accruing to a particular built form. Yet the only narrative that can reliably continue to have power in the life of a building is the narrative that the building itself remembers, that the building itself embodies and contains - the narrative that is given in the singular materiality of a specific built form and the place it occupies (a point that follows from the general character of the relation between creative intention and creative work - see Malpas 2011).

\section{The ontology of building and the ethics of memory}

The implication of memory with building concerns the very nature of building, as well as of the human. It provokes a number of questions. How, for instance, is one to build in a way that acknowledges the implication with memory? What memories and forms of memories pertain to different forms of building? What difference would it make to the built environment if memory were to become an explicit element in architectural thinking and making? These seem to me to be important questions even though they are not commonly asked or addressed. Just as much of my account here has remained at the level of a sketch rather than a fully realised study (and nowhere more so than when it comes to matters of architectural practice), so I have not the time or space to try to respond to these questions here - although some indication of the direction in which I might move should be evident by my comments above. There is, however, another matter that comes to the fore once one begins to take seriously the connection of place with memory, and of both with building as well as architecture: the matter, not only of ontology, but of ethics. As I use it here, ethics is not about some theory of the "good" or the "just". Instead it essentially concerns our attentiveness to the remembered place and the placed memory - our attentiveness to the placedness of the human and the human-ness of place. Once we understand the essential interconnection of the 
concepts at issue here, and once we understand the materialised, placed character of human being, then the task of building, and of architectural design, becomes a task from which the ethical can never be excluded, and that is fundamentally tied to matters concerning the very formation of the human.

When we build we do indeed build memory, and every building carries memory within it. What this means, however, is that when we neglect the memorial character of building, and so the way memory must also enter into building construction and design, we neglect an essential element in what it is to build. We thereby misunderstand building, and we also misunderstand ourselves. The implication of the self in architectural practice is, of course, part of a larger hermeneutic structure of self-implication that characterises all modes of understanding, inquiry, and creation. Yet such self-implication takes on a particular form in architecture, since the working out of the self that occurs in architecture is also externalised and concretised - it is a reciprocal shaping of self and built form as that occurs in and through the engagement with place. Here is the real reason for the importance of the investigation into the ontology of architecture: that investigation cannot but force us back to an investigation of the properly human context of architectural practice, since that is what is at issue when we inquire into the character of architecture as an engagement with place. The engagement with place is also, by its very nature, an engagement with the human. The human dimension of architecture is something that the presentism of modern architectural theory and practice often effaces. That it does so is no accident, for the effacing of memory is indeed an effacing of the human. It is also, by the same token, an effacing of both ontology and of ethics. 


\section{References}

Améry, J. (1998). How much home does a person need? In J. Améry, At the mind's limits: Contemplations by a survivor on Auschwitz and its realities (S. Rosenfeld \& S. Rosenfeld, Trans.). Bloomington: Indiana University Press.

Bachelard, G. (1969). The poetics of space (M. Jolas, Trans.). Boston, Mass: Beacon Press.

Baird, G. (2004). Criticality and its discontents. Harvard Design Magazine, 21, 16-21.

Hays, M. (1984). Critical architecture: Between culture and form. Perspecta, 21, 14-29.

Benjamin, A. (2006). Surface effects: Borromini, Semper, Loos. Journal of Architecture, 11, 1-35.

Borges, J. L. (1962). Funes the memorious. In A. Kerrigan (Ed.), Ficciones.

London: Grove Weidenfeld.

Casey, E. S. (2000). Remembering: A phenomenological study, 2nd edn. Bloomington: Indiana University Press.

Hicks, D. \& Beaudry, M. C. (Eds.). (2010). The Oxford handbook of material culture studies. New York, NY: Oxford University Press.

Leatherbarrow, D. \& Mostafavi M. (1993). On weathering: The life of buildings in time. Cambridge, Mass.: MIT Press.

Lehtimaki, K. \& Neuvonen, P. (Eds.). (2004). Richard Leplastrier - Spirit of Nature Wood Architecture Award 2004 (G. Griffiths, Trans.). Helsinki: Rakennustieto Publishing.

Luria, A. R. (1987). The mind of a mnemonist (L. Solotaroff, Trans.). Cambridge, Mass.: Harvard University Press.

Malpas, J. (1999). Place and experience. Cambridge: Cambridge University Press.

Malpas, J. (2007). Heidegger in Benjamin's city. Journal of Architecture, 12, 489-499.

Malpas, J. (2010a). The beginning of understanding: Event, place, truth. In J. Malpas \& S. Zabala (Eds.), Consequences of Hermeneutics (261-280). Chicago, III.: Northwestern University Press.

Malpas, J. (2010b). Truth, narrative, and the materiality of memory: An externalist approach in the philosophy of history. Journal of the Philosophy of History, 4, 328-353.

Malpas, J. (2011). Objectivity and self-disclosedness: The phenomenological working of art. In J. Parry (Ed.), Art and phenomenology (54-76). London: Routledge.

Malpas, J. (2012a). Heidegger and the thinking of place. Cambridge, Mass.: MIT Press.

Malpas, J. (2012b). Putting space in place: Philosophical topography and relational geography. Environment and Planning D: Society and Space, 30, 226-242.

Malpas, J. (2013, forthcoming). The remembrance of place. In A. Cruz (Ed.). Essays in honor of Edward S. Casey. New York, NY: Continuum.

Proust, M. (1995). In search of lost time (L. Davis et al., Trans.). London: Penguin.

Sebald, W. G. (1998). The rings of Saturn (M. Hulse, Trans.). London: The Harvill Press.

Somol R. \& Whiting S. (2002). Notes around the Doppler Effect and other moods of Modernism. Perspecta, 33, 72-77.

Vidler, A. (1992). The architectural uncanny: Essays in the modern unhomely. Cambridge, Mass.: MIT.

Weil, S. (1971). The need for roots: Prelude to a declaration of duties toward mankind (A. Wills, Trans.). New York, N. Y.: Harper \& Row.

Yates, F. (1974). The art of memory. Chicago, III.: University of Chicago Press.

Zumthor, P. (1999). Thinking architecture. Basel: Birkhäuser.

My thanks to the anonymous reviewers at Interstices for their comments and advice on the original draft of this essay. I am also extremely grateful to Mat Hinds and Leigh Woolley for their suggestions and corrections - and for their continuing willingness to respond so generously to my "naïve" approach to architecture and design. 